A. M. BALDIN, W. I. GOLDANSKIJ, I. L. ROSENTAL

Kinematik der Kernreaktionen 

A. M. BALDIN, W. I. GOLDANSKIJ, I. L. ROSENTAL

\title{
KINEMATIK DER KERNREAKTIONEN
}

\author{
Übersetzt und in deutscher Sprache herausgegeben \\ von \\ Prof. Dr. phil. habil. JOSEPH SCHINTLMEISTER \\ unter Mitwirkung von \\ Dr.-Ing. KARLHEINZ MƯLLER
}

Autorisierte Ausgabe

Mit 69 Abbildungen und 57 Tabellen

A K A D E M I E - VE R LAG - B E R L I N

1963 
Балдин, Александр Михайлович · Гольданский, Виталий Иосифович · Роәенталь, Иосиф Леонидович

\title{
Кинематика ядерных реакций
}

Erschienen im Staatsverlag für physikalisch-mathematische Literatur Moskau 1959

\author{
Erschienen im Akademie-Verlag GmbH, Berlin W 8, Leipziger StraBe 3-4 \\ Copyright 1963 by Akademie-Verlag GmbH \\ Lizenznummer: $102 \cdot 100 / 820 / 63$ \\ Gesamtherstellung: Druckhaus „Maxim Gorki", Altenburg \\ Bestellnummer: $5480 \cdot$ ES 18 B 7
}

